\title{
Expansion of e-Commerce Coverage to Unreached Community by using Micro-Finance Infrastructure
}

\author{
Ashir Ahmed \\ Department of Advanced Information Technology \\ Kyushu University, Fukuoka, Japan
}

Kazi Mozaher Hossein

Department of Advanced Information Technology

Kyushu University, Fukuoka, Japan

Md. Asifur Rahman

Department of Advanced Information Technology

Kyushu University, Fukuoka, Japan

\author{
Takuzo Osugi \\ Institute for Academic Initiatives \\ Osaka University, Osaka, Japan
}

Akira Fukuda

Department of Advanced Information Technology

Kyushu University, Fukuoka, Japan

Hiroto Yasuura

Department of Advanced Information Technology

Kyushu University, Fukuoka, Japan

\begin{abstract}
Most people at the BOP (base of the economic pyramid, the largest but the poorest community in the world comprising $69 \%$ of world population) do not have access to ecommerce services. The way e-commerce is designed and practiced today does not enable their participation. The reasons are: their purchasing power is low, they do not have any means to make online payments, and there is no infrastructure to deliver the purchased items to their doors. To enable the participation of the people at $\mathrm{BOP}$, we propose an e-commerce framework by engaging MFI resources and our recently developed ePassbook system. This paper shows how the BOP community can enjoy the benefits of the e-commerce service by using the proposed model. The advantages of making ecommerce available to the BOP are discussed, in addition to the challenges involved in implementing the model.
\end{abstract}

Keywords-ICT; BoP; microfinance; E-commerce; social services; ePassbook

\section{INTRODUCTION}

E-commerce over the Internet has been in practice for more than a decade. E-commerce enables people to purchase products from a remote place at any time of the day and get the desired products delivered to their doors. It saves time, money and labor. A product seller can upload the product information on the web and can breach the boundaries of the local market to reach the customers on a global scale. A customer, on the other hand, can search for a desired product in a much more extensive selection space, and can find the suitable product. In this way, e-commerce brings benefits for both the buyers and sellers as indicated by the trend in e-sales. From 2006 to the second quarter of 2015, retail e-sales have increased at an average annual growth rate $35 \%$, compared with $7.2 \%$ for the total retail sales in United States [1]. In order to purchase a product through a web-based e-commerce service, a customer needs access to the Internet and an online payment mechanism, typically a credit card. Presently $43 \%$ of world population has access to the Internet, however, 4 billion people from developing countries remain offline, representing $2 / 3$ of the population [2]. Apparently, $16.42 \%$ people hold a credit card (this figure is assumed from the fact that 3.3 billion cards were issued globally and on an average each individual holds 3 credit cards). How about the remaining majority of the population? Do they not have any interest in participating and enjoying the benefits of e-commerce? These unreached are the 4 billion people at the BOP [3], comprising $69 \%$ of the world population shown in Fig.1. Despite their low income and limited purchase capacity, they make frequent purchases within their limited spending power [4]. According to [3], there is money at the BOP and their purchasing habits mean that they actually pay more for certain items than wealthier customers. This BoP penalty is the consequence of local monopolies, inadequate access, poor distribution and strong traditional intermediaries.

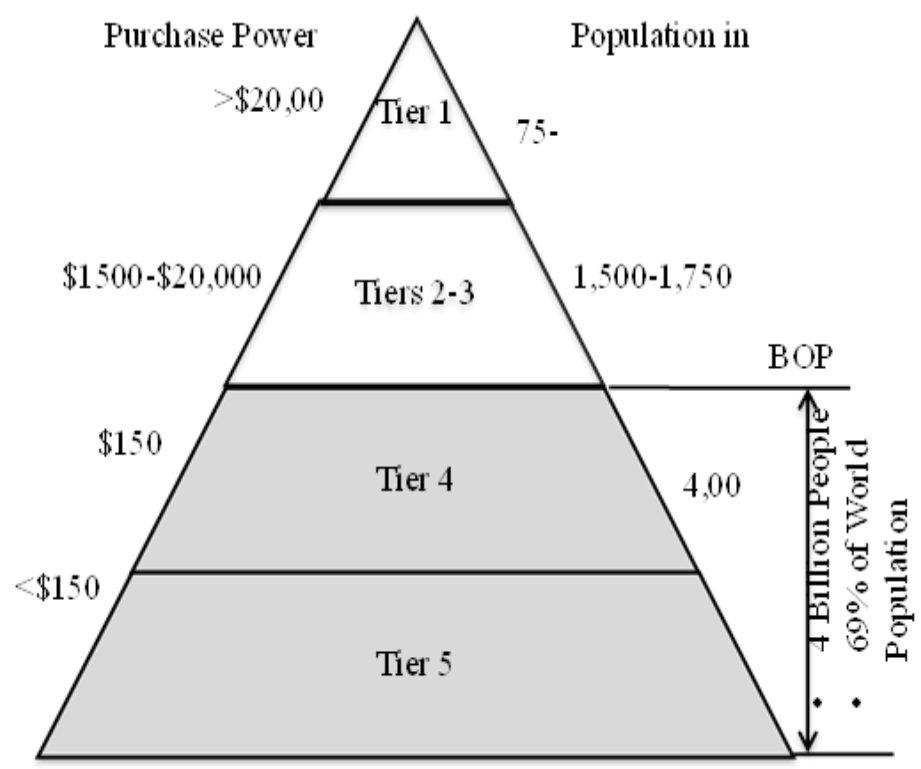

Fig. 1. Base of the Pyramid (BOP), the largest but the poorest community in the world 
In this article, we introduce e-commerce system to this unreached community. Our model utilizes the MFI resources to act as an intermediary between the supplier and the consumer. In Bangladesh, around 20 million people representing BOP have access to micro-finance institutions (MFI) [7]. They carry out financial transactions in a regular basis with their associated MFIs. An MFI member not only borrows money from the MFI but also maintains a savings account. The accumulated savings of the 8.3 million Grameen Bank members is around 1.2 billion US dollars [8].

An MFI officer meets 300-500 members (clients of MFI) once a week. An MFI officer can compile a list of desired products from the members and a bulk purchase request can be handled on behalf of the members. It can be assumed that MFI officers have access to the Internet and know how to operate a computer. The members can withdraw their savings to purchase their daily needs such as soap, shampoo, rice, wheat, salt, and spices. They can receive the same product at a cheaper price through e-commerce. 8.3 million members in Grameen Bank alone have 30 million family members. If we consider soap as a product and one family consumes at least a piece of soap per month, 8 million pieces of soap per month will be the projected market size. An MFI like Grameen can make a business agreement with a soap producer ensuring 8 million soap purchases per month. The soap producer would find it viable to offer a different business plan for such a giant prepaid customer. If we include other two MFIs in this service, 20 million soap bars can be sold in a month. In this way, MFI can offer an effective e-commerce service to its members.

Introducing e-commerce to the BOP, may affect the present non-e-commerce based businesses. The current business incentives also need to be considered. Selecting the products for the products for this system we need to carefully choose the products so that they do not affect the present business system but at the same time give a significant price advantage. At the consumer level a person at the BOP purchases the local produce like rice and lentils from the local market where a BoP penalty is rarely applicable. For consumers the list may contain edible oil, soap, sugar, salt etc. the items that is not produced locally and traditionally marketed from a central location. Our system would allow them to access the central supplier directly, eliminating the intermediary and increasing access to overcome the poor distribution problem. There are few other items that the consumers purchase seldom but the local retailers visits the wholesale market frequently. Keeping those items in the list would also allow the BoP people to purchase at a lower price at the time of necessity. The relevant items might be electrical items (bulbs, cables, sockets), traditional clothing (lungi, saree etc.). The list should also include seasonal items to address the demand when applicable. It is our intent to arrange the system in such a way that the gap between producer and consumer is reduced and an unnecessary intermediary disappear.

There are more advantages to including MFI in the BOP ecommerce model. In the present web-based e-commerce system, buyers do not feel comfortable sharing personal information and credit card information on the web. In MFI, the members have long credit relationship with the MFI officers. As the members meet their officer every week, they have some sort of trust relationship with the officer. The officer can collect the money from their savings and forward the money to the supplier of the product. If the seller is not a Grameen Bank member, the money can be sent to his bank account by using a third party bank.

The remainder of the paper is structured as follows: in section 2, we explain the present e-commerce system, the requirements and the limitations. We propose a model involving the MFI resources in Section 3. The advantages of the proposed model and the challenges are also discussed. Section 4 has the conclusion and the future works.

\section{PRESENT WEB-BASED E-COMMERCE SYSTEM}

\section{A. Present E-Commerce}

In a typical e-commerce scenario, a buyer visits a website. The website contains product information including the product stock status and the price. The buyer fills up a purchase order form which contains the list of items. Upon completing the purchase order form, the buyer is asked to make an online payment using some online payment system e.g. a credit card. The credit card details are communicated through a standard secured communication process. Once the payment process is complete, the list of ordered items is sent to the supplier along with the payment advice, the supplier delivers the purchased items accordingly. Fig. 2 shows a typical e-commerce model. There are three major stakeholders in the present e-commerce system:

Buyer: is a person who buys a product. A buyer needs a means to find the product catalogue to select the product, a means to communicate with the seller to place the order and a method to make the payment. In a web-based e-commerce system, a buyer visits the product website, selects the product, makes the payment by credit card or other online transaction system. Upon confirming the payment, the supplier arranges for the product to be delivered to the address specified by the buyer.

In addition to online services, a buyer can also obtain product information through TV commercials or published catalogs and leaflets. The purchase order also can be processed by telephone, fax or postal order. The payment options are both prepaid and postpaid. Prepaid payment systems include credit cards and bank transfer. Some countries, such as Japan, have post-paid process where the money is collected when the product is delivered.

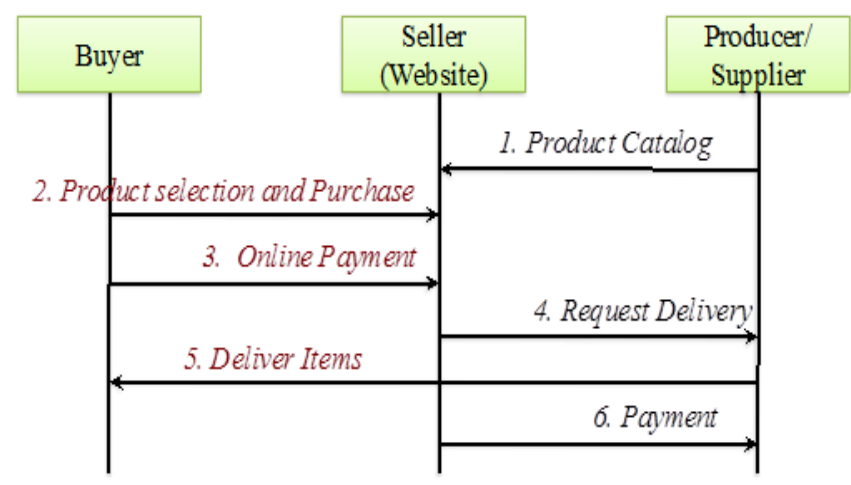

Fig. 2. Typical e-Commerce System Scenario 
Seller: is a person who sells products. In a web-based system, a seller is a website that interfaces with buyers. Such a website offers a product catalog, an interactive interface to receive customers' preferences, a shopping cart system for the purchasing process and an online payment system. The website needs to ensure a secure system to handle customer information.

Supplier: receives purchase orders through the web and checks the payment process. A supplier needs store houses for the products. The storehouses can be either centralized or distributed. In order to minimize the delivery time, distributed suppliers can deliver the product from the closest distribution point. A supplier keeps the products in its possession and supplies them to the customers. A supplier can be a producer of the product, its representative, an agent or a distributor. A supplier also ensures the delivery of the product and post-sales services.

\section{B. Limitations of the Present E-Commerce System}

The present web-based e-commerce system brings enormous advantages to society. However, the participation of the BOP community is missing. A traditional business targets a consumer segment considering their purchasing power. The cost of maintaining the infrastructure and executing a delivery can be justified by a minimum transaction value. At the BOP, people's income is low and their purchasing power is limited. The purchase volume is not within the range to justify the overhead. Infrastructure support is also required for ecommerce. The following limitations kept the BOP community unreached and deprived them of the advantages of the ecommerce system.

1) Internet access: The BOP community usually does not have an affordable Internet access. As a result, online purchase orders cannot be made.

2) Electronic payment system: The BOP hardly has any means of electronic payment (credit card or PayPal account), nor do they have any communication infrastructure to support online payment facilities.

3) Lack of awareness of advance payment: The advantages of advance payment for products are not clear. BOP usually make face-to-face purchases and pay on the spot. Prepaid-based telephony services are popular because the charges are well defined and they consume product right away.

4) Home delivery: delivering a small supply to an individual address makes the delivery cost too high to justify.

5) Return handling: return of a small supply makes it difficult to plan an appropriate model. On the other hand, the BOP community would feel insecure bargaining with remote suppliers.

6) Post-sales customer service: providing post sale customer service to the BOP community is difficult because there is no communication infrastructure to support such a service.

\section{E-COMMERCE USING MFI RESOURCES}

In this section, first we describe how MFI structure and show how MFI resources can meet the requirements of ecommerce for the poor community. The advantages as well as the impact are also discussed.

\section{A. MFI Resources}

Microfinance institutions can be an excellent vehicle to provide e-commerce services to the BOP. MFIs have been successful in accessing the rural poor and introducing financial services to them. Fig. 3 shows the operations and management system of Grameen Bank.

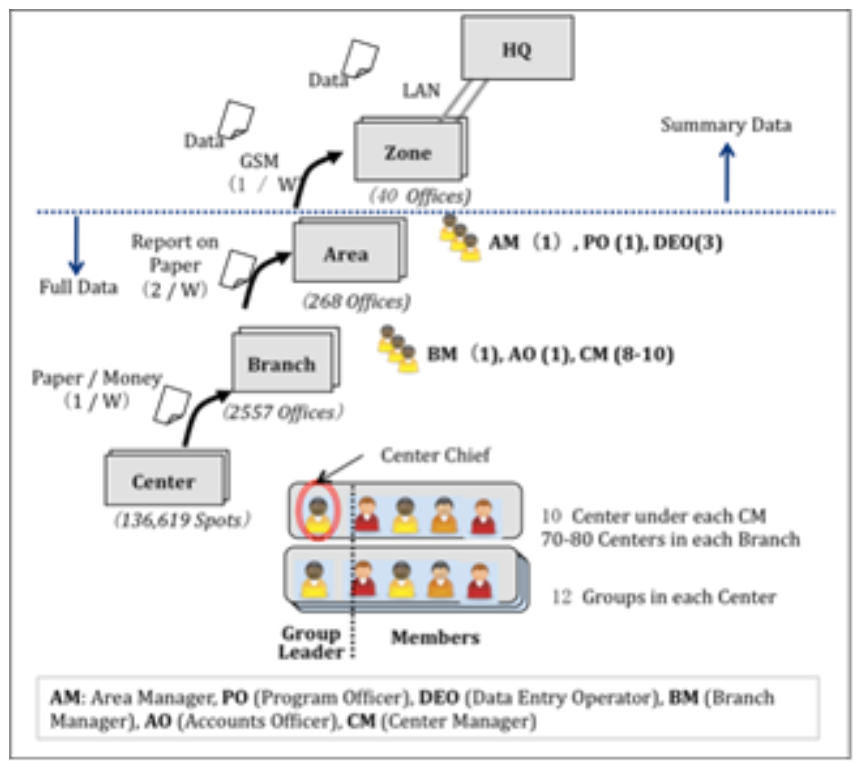

Fig. 3. Grameen Bank Operational Infrastructure

Like other Microfinance Institutions (MFIs), Grameen Bank provides financial services to poor people in the remotest parts of the country through a very efficient and closely monitored human network. In Grameen Bank, 8.3 million members throughout the country, are visited by 20,000 center managers once a week. A center manager has the socioeconomic status of the affiliated members. These center managers deliver financial services (savings, loan, insurance, remittances etc.) to the members. The group solidarity and rapport of the MFI officer with the center members are the main driving forces behind successful operation of an MFI. A center manager belongs to a branch supervised by the branch manager. Branches are the main activity unit of any MFI which works on and maintains detailed data of the operations. Branches are closely monitored by mid-level managers at the area offices. These mid-level managers work on summary data aggregated from each branch. Top level managers in the headquarters and zonal offices manage the overall operation. This is how Grameen Bank's human network is connected.

MFI officers developed good relationships with the rural poor in terms of trust in financial transactions. In our previous work [5], we identified that MFIs have created a strong network among the BOP population. 
Every 5 miles Bangladesh, there is an MFI office provided by at least one MFI: either by Grameen, BRAC or ASA. These three organizations serve more than 18 million members, through 75,000 field staff workers distributed among 8,000 branch offices in the country. An MFI officer visits 300-500 people per week. The network is an efficiently managed business with a yearly turnover of around 10 billion US dollars. The collective savings is also significant, at around 2 Billion US dollars. The relationship between the members and the MFI develops over decades. Most importantly, MFIs have detailed records of their members' credit worthiness. They also have moderate record of their transaction abilities over a period of time. Hence, it can be assumed that if we can use the harmony among the members of an MFI and access them through that MFI, a good business model can be generated. For example the daily consumption amount of edible oil is very low for one family. But collectively for 2000 members in a branch, the consumption amount is significant enough to make any supplier interested for business.

TABLE I. E-COMMERCE COMPONENTS AND MFI RESOURCES TO MEET THE REQUIREMENTS

\begin{tabular}{|l|l|}
\hline Components & \multicolumn{1}{|c|}{ MFI resources } \\
\hline Access to & $\begin{array}{l}\text { The end user (MFI member) may not have access or } \\
\text { skills to use the Internet. An MFI officer, on their } \\
\text { behalf, accesses the product information for the client. } \\
\text { A printed product catalog can be supplied to the } \\
\text { members to mark the desired items. An MFI officer } \\
\text { then can consolidate and submit the order through the } \\
\text { web. }\end{array}$ \\
\hline $\begin{array}{l}\text { Electronic } \\
\text { payment } \\
\text { system }\end{array}$ & $\begin{array}{l}\text { The eCash service provided by the ePassbook makes } \\
\text { electronic payment possible. eCash is capable of } \\
\text { handling payment from the cardholder's account to any } \\
\text { other account within the same system. }\end{array}$ \\
\hline $\begin{array}{l}\text { Advance } \\
\text { payment }\end{array}$ & $\begin{array}{l}\text { Trust between the MFI and the members are leveraged } \\
\text { to make this possible. The MFI would negotiate a good } \\
\text { price discount for its members. }\end{array}$ \\
\hline Home delivery & $\begin{array}{l}\text { Individual delivery of small supply is expensive. MFI } \\
\text { can use their meeting place for collecting purchased } \\
\text { products where the MFI officer meets every week. The } \\
\text { officer can also ensure safe product delivery. }\end{array}$ \\
\hline $\begin{array}{l}\text { Return } \\
\text { handling }\end{array}$ & $\begin{array}{l}\text { Return handling and warranty claims can be managed } \\
\text { and negotiated by MFI officers. It gives the confidence } \\
\text { to the MFI members of dealing with the suppliers. }\end{array}$ \\
\hline $\begin{array}{l}\text { Customer } \\
\text { service }\end{array}$ & $\begin{array}{l}\text { Customer services including return handling, } \\
\text { complaints and other negotiation activities can be } \\
\text { offered by the MFI. }\end{array}$ \\
\hline
\end{tabular}

In Section 2, we discussed the limitations of the present ecommerce systems. These limitations can be overcome if an MFI officer could be involved in e-commerce businesses. The advantages of involving an MFI officer in the system are:

a) Instead of a logical webpage, buyers can deal with a person to verify and get better understanding of product. Furthermore, they have the option to discuss with their peer group members. This also keeps a witness on the transaction. The trust level is significantly better than with a black box.

b) Buyers do not feel comfortable providing credit card information on the web. An MFI officer is trusted by the MFI members. Thus, members will feel more comfortable by being able to pre-pay for the e-commerce products. The peer witness also contributes to the creation of further trust. c) Internet and credit cards used in today's e-commerce are not available to people in the BOP. Again, the concept of pay first and get the supply afterwards is not familiar to them. In our proposed model, the MFI officers are trusted since these officers oversee the members' monetary transactions every week. Thus, the MFI officer can work as a replacement for the website in traditional e-commerce. For secured order placement and payment, the MFI will use the ePassbook and related infrastructure.

\section{B. ePassbook:}

ePassbook is an electronic card developed by us for microfinance members to maintain their financial records. The core component of this card is an IC chip which is common in other smart cards such as bankcards and employee cards. The developed ePassbook offers multiple services especially for the BOP, including microfinance, health, and e-cash. It keeps both MFI and health records. A user can view the records by using the display attached to the card. Traditional cards do not have this facility. ePassbook can transfer records by using the inbuilt RFID communication interface. An ePassbook reader is also developed for this purpose. An MFI officer with an "ePassbook reader" can communicate with the ePassbook device to update the bank transaction. A doctor in a hospital or clinic can access the health records. Now we want to use the same device for our proposed e-commerce framework.

\section{E-Commerce with MFIs Involvement: The Proposed Model}

Fig.5 explains the proposed system. The MFI members are the target consumers in this model. An MFI officer representing the consumers will play the role of intermediary. An established web platform for the villagers (gramweb.net) will contain the product information. The suppliers are selected based on their agreement with the MFIs.

1) The suppliers share their product catalog on a specified website. GramWeb [7] is a website containing village specific information. The local villagers own and maintain their village sites. Therefore, it will be effective for the suppliers to distribute village-specific catalogs considering their needs. As not all villagers have access to the Internet, these unreached people will not be able to view an online product catalog. The MFI officer can fill the gap.

2) An MFI officer will have an updated printed catalog to share with the MFI members. The catalog will be villagerfriendly so that low-literate villagers can easily understand and use it for placing orders.

3) The consumers will select products from the catalog and put the order in a pre-printed form. An MFI officer meets 300-500 people per week. This is the customer segment that one MFI officer can cover per week.

4) An MFI member holds an ePassbook. The ePassbook will allow the MFI members to use their savings money to pay to a third party through the MFI headquarter. The MFI officer transfers the order value from the member's savings account to a special e-commerce account in the branch and records the transaction ID on the order form. 
5) The MFI officer collects all the individual orders and enters them in the website on behalf of the members. The MFI officer needs to be properly authenticated by GramWeb.

6) GramWeb then proceeds with a delivery request to the supplier.

7) The supplier delivers the products to the place where MFI members meet the MFI officer. In Grameen, the place is called a center office.

8) The MFI officer then processes the final payment to the supplier.

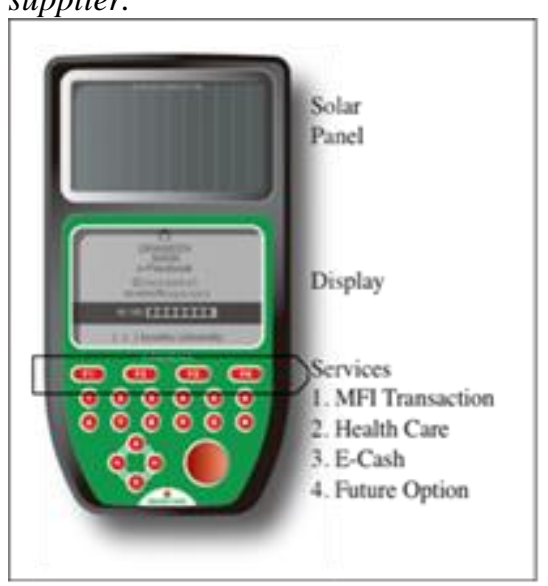

Fig. 5. ePassbook for micro-finance borrowers

In this way, e-commerce services can be reached to the unreached, the largest socio-economic group in the world.

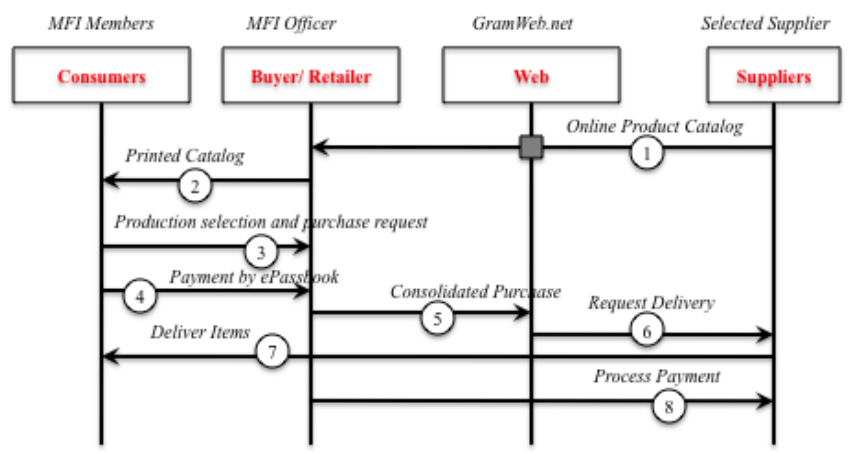

Fig. 4. eCommerce Model for BoP consumers using MFI Resources

\section{Advantages}

The proposed model brings the following benefits to its stakeholders-

A. Villagers: The villagers include the MFI members, local retailers and other villagers. By utilizing the proposed scheme, villagers can purchase reliable branded products at a cheaper price. Local retailers might seem to lose their business if MFI starts doing this business. However, they can also use this channel to purchase items directly from producers at a lower cost. Usually these retailers go to the wholesale shops individually which involves transportation costs and time. The proposed model offers a single trip for all necessary products. The transportation costs and time will be significantly minimized [Fig. 6].
B. The MFI: e-commerce will be a value added service for the MFI. Other benefits include: (a) Increased trust/loyalty from the members, (b) More savings from the members (c) Financial benefit from the advanced payment by the members (d) Wider transaction record (e) Additional line of revenue

C. Researchers: It is possible to archive the list of purchased items. The archive can be a good resource for analyzing and determining BOP purchase pattern, food behavior, and nutrition facts. Predictions about the future market can also be made.

D. Suppliers: Having a contract with giant a microfinance institution with millions of customers will provide an effective business opportunity. Analyzing the business trend, suppliers will be able to handle a larger market with reduced effort in an organized way.

E. Producers: The producer will receive first hand and regular consumer feedback. It will be possible to develop new products to meet the specific demands of the BOP. This will also help reduce copies, fakes and other undesirable items being peddled to the BOP market.

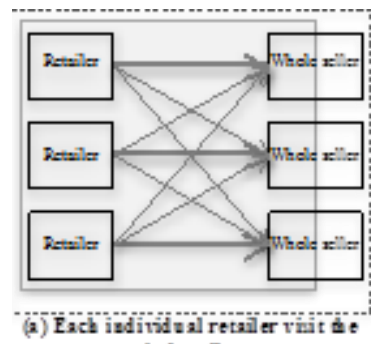
whole veller:

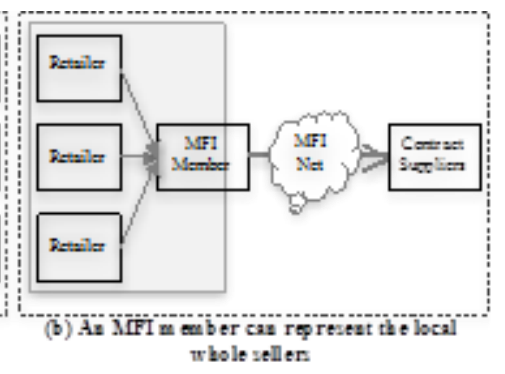

Fig. 6. Transportation cost saving for the individual retailers

\section{E. Scope and Challenges}

The objective of the proposed system is to introduce ecommerce services to the unreached community. To deliver the service, the proposed system places MFI officers at the center point of service delivery. Therefore, any person who is a member of an MFI is within the scope of this service model. Products to be handled in this system are selected according to the following features: (a) Familiarity of the product: Especially the branded items with the price tagged (b) Transportability: Products that are neither fragile nor perishable, and (c) Affordability: The optimum size of the product in an affordable range.

The proposed system will face following challenges:

(a) Business of the existing retailers: Presently, the retail business is channeled by two to three tiers of distributors. A large number of retailers are spread over the country. The new model of business would reduce their market share significantly, especially when we consider Bangladesh where every family in the BOP is attached to at least one MFI.

(b) Postpaid vs. prepaid: Uncertainty of income is a major problem for BOP people [8]. Hence they maintain a credit line with retailers. To address this problem, we propose that MFI can introduce a suitable loan product analyzing the members' credit and repayment history. The MFI would ensure a good 
bargain from the supplier, which would act as an incentive for advance payment.

(c) Home delivery: Home delivery might be a problem in low density, remote, and hard to reach parts of the country. Where residents used to walk or ride on small country boat to travel the long distance to the market place for the purchase of consumables.

\section{CONCLUSION AND FUTURE WORKS}

Access to product information, online payment mechanism and product delivery channel are the major components to provide e-commerce services. Developing the necessary infrastructure can be a way to allow 4 billion people at the BOP to enjoy e-commerce benefits but it may take decades to make this happen. We proposed an alternative solution of using Microfinance resources and the ePassbook we have developed. MFI officers visit their clients once a week and have strong financial trust. The ePassbook allows a borrower to transfer money electronically. The proposed model brings benefits to all stakeholders. The first hand benefit goes to the villagers who have been deprived of e-commerce service. The microfinance industries will be able to keep more savings in hand. The suppliers can benefit from bulk orders from the microfinance institutions. The producers will be able to reach the unreached with their products. This will also open a new window for researchers to analyze the market trends and consumption patterns, including issues related to health. A concern remains about how the introduction of e-commerce through MFI in the BOP community will affect the local retailers.

\section{ACKNOWLEDGMENT}

This work has been supported by Kyushu University Research Superstar Program (SSP), Special Coordination Funds for Promoting Science and Technology, originating from the Ministry of Education, Culture, Sports, Science and Technology (MEXT), Japan.

\section{REFERENCES}

[1] U.S. Census Bureau News, U.S. Department of Commerce, Washington, D.C. 20233, August 17, 2015

[2] ICT facts and figures, the world in 2015, ICT Data and Statistics Division, Telecommunication Development Bureau, International Telecommunication Union, Geneva, May 2015

[3] CK Prahlad, 2004. "The Fortune at the Bottom of the pyramid". Watson school Publishing, New Jersey, USA

[4] SMS Zabir, A Ahmed, H. Yasuura, "Digital Divided: The Amazing Fact at the BOP", Proceedings, IADIS International Conference ICT, Society and Human Beings (MCCSIS 2008), IADIS Press, July 2008

[5] Asifur Rahman, Ashir Ahmed, Osugi, Takuzou, "Key challenges to the expansion of micro finance institutions in Bangladesh: Case studies on Grameen, ASA, BRAC", Bulletin of Kyushu University Asia Center Vol. 4 March 2101, Page 85-93

[6] Yunus, Muhammad (1999). "Banker to the Poor (First ed.)". PublicAffairs Publishing, New York City, USA

[7] Ashir Ahmed, "An information production and ownership platform for BoPers", Proceedings. IADIS International Conference ICT, Society and Human Beings (MCCSIS 2009), IADIS Press, June 2009, pp. 147-154, ISBN: 978-972-8924-82-9

[8] Darly Collins, Jonathon Morduch, Stuart Rutherford, Orlanda Ruthven, 2009. "Portfolios of the Poor". Princeton University Press, New Jersey, USA 